should provide a basis for the accurate and reliable mortality statistics that are essential as a basis for epidemiological medical research, which seems likely to become of increasing importance in the future.

1 Home Office, Report of the Committee on Death Certification and Coroners. London, H.M.S.O., 1971. Price $£ 2.35$.

\section{Pacemakers for Heart Block}

About 1,800 patients in Britain are at present being treated with implantable cardiac mercury-cell pacemakers. Since pacemakers were first introduced in Sweden and the United States in the late 1950s their reliability has improved, so that implanted models now usually achieve lifetimes of at least two years, with occasional examples exceeding three years. The failure rate within the first year of use is very low, but exhaustion of the mercury cells used to power these devices then becomes increasingly important. ${ }^{1}$

An alternative approach is that pioneered by L. D. Abrams and his colleagues in Birmingham, ${ }^{2}$ who use an implantable receiving coil connected to the heart with an external generator transmitting power across intact skin by induction; about 400 patients are now being treated this way. Clinical results with the two methods are comparable, and the mortality of patients with chronic heart block is approximately $10 \%$ within the first year. ${ }^{3}$ This contrasts with the one-year mortality of $40 \%$ among patients with heart block not related to cardiac infarction, and not induced by drugs, who were treated medically. 56 The improved survival achieved by paced patients is maintained for at least five years, and results are particularly encouraging in patients of working age. ${ }^{7}$

The hospital mortality for pacemaker implantation is about 1 to $3 \%$ whether the electrode is passed to the right ventricle through the venous system or attached surgically to the epicardial surface of the heart. ${ }^{8}$ The indications for pacing are now more numerous than a few years ago, and in many centres in the United States, Canada, France, Germany, and Scandinavia, a pacemaker is always implanted when persistent intermittent or complete heart block has been diagnosed. Since the first Stokes-Adams attack may be fatal there is increasing support in the U.S.A. and parts of Europe for prophylactic implantation in patients with right bundle branch block and left anterior hemiblock, together with delayed conduction in the left posterior fascicle of the conducting system. In the United States approximately 5,000 pacemakers are implanted every month, and about one person in every 5,000 of the population now has one. ${ }^{10}$ This is expected to double within a few years ${ }^{10}$ but is already six times the level in Britain. During 1969 in Sweden initial implantations were carried out in 96 patients per million population, and other Scandinavian countries reached a level of approximately 40 per million. ${ }^{9}$ The equivalent figure in Britain was only 9 per million. ${ }^{4}$ Unless chronic heart block is very much less common in Britain than in other countries it appears that a large number of patients who might benefit from pacemaker therapy are remaining untreated.

It is generally accepted that a recent, proved StokesAdams attack, effort dyspnoea, or frank heart failure due to bradycardia justify pacemaker implantation. Treatment with long-acting isoprenaline has been disappointing, partly be- cause symptoms frequently recur after a short time; though a few patients can be maintained in this way the overall mortality is higher and this approach has been abandoned in many centres. There are no age limits for cardiac pacing, which has been used in young babies and in at least one patient aged 100 years. In many cases chronic heart block is due to fibrosis of conducting tissue without significant muscle damage, ${ }^{11}$ and so patients with a pacemaker can be encouraged to lead normal lives and enjoy leisure activities such as golf or swimming.

The induction type of pacemaker is particularly suitable for young children because only a small receiving coil need be implanted. The most reliable type of implanted pacemaker is still the simple fixed rate unit, but this competes with the normal rhythm in patients with intermittent heart block producing palpitations and occasionally wide variations in blood pressure, which may cause symptoms. Ventricular programmed pacemakers (demand pacemakers) monitor spontaneous cardiac activity and do not stimulate unnecessarily, though their greater complexity results in a shorter battery life. When the batteries of implanted pacemakers near exhaustion, or if one cell fails prematurely, the discharge rate alters; taking the pulse is a simple and informative test provided continuous pacing is present. If spontaneous, non-paced, activity is present an electrocardiogram will usually be required to determine the pacemaker rate. A change of five beats per minute is a sign that the unit should be replaced. When an induction pacemaker is used the external batteries can easily be changed by the patient, and this manoeuvre may have to be performed every two or three weeks with the potential loss of pacing for a few beats on each occasion.

There are a few patients in heart block who manage well without pacing, often for many years, but these are a selected group who have survived the early months, and many have symptoms which restrict their lives. Since a pacemaker might well lessen these restrictions by increasing the ventricular rate its use should always be considered.

\footnotetext{
${ }^{1}$ Harthorne, J. W., Leinbach, R. C., Sanders, C. A., and Austen, W. G., Annals of the New York Academy of Sciences, 1969, 167, 1008.

Abrams, L. D., Hudson, W. A., and Lightwood, R., Lancet, 1960, 1, 1372.

3 Torresani, J., Bernand, Y., Monties, J. R., and Jouve, A., Annals of the New York Academy of Sciences, 1969, 167, 995 .

4 New York Academy of Sciences, 1969, 167, 995. 1971, 20, 295.

Sowton, E., Annales de Cardiologie et d'Angiologie, 1971,

' Johansson, B. W., Acta Medica Scandinavica, 1966, 180 . Academy of Sciences, 1964, 3, 835 .

7 Sowton, E., and Flores, J., Bulletin, New York Acad Med., 1971, 47, 999.

${ }^{8}$ Morris, J. D., and Judge, R. D., Annals of the New York Academy of Sciences, 1969, 167, 987.

- Karlof, I., and Lagergren, H., Annales de Cardiologie et d' Angiologie, 1971, 20, 313 .

10 Parsonnet, V., Annales de Cardiologie et d'Angiologie, 1971, 20, 287.

11 Harris, A., Davies, M., Redwood, D., Leatham, A., and Siddons, H., British Heart Fournal, 1969, 31, 206.
}

\section{Neurology of the Leukaemias and Lymphomas}

Though neurological syndromes are a recognized complication in the leukaemias and lymphomas, their precise frequency has been studied relatively rarely. Thus, a recent report by S. Currie and R. A. Henson ${ }^{1}$ has helped to put matters in perspective by clarifying the prevalence of neurological problems in lymphoproliferative and myeloproliferative diseases. 
These authors employ "reticulosis" as a blanket term to embrace Hodgkin's disease, lymphosarcoma and follicular lymphoma, myeloma, polycythaemia vera, reticulum cell sarcoma, and various types of leukaemia. Of the total of 774 patients studied $26 \%$ developed neurological syndromes. About half of these were due to local deposits of neoplastic tissue, most of them involving compression of the spinal cord or nerve roots. Of the non-metastatic complications, half (about $25 \%$ of all neurological manifestations) were caused by infections, presumably related to impaired immunological reactions, herpes zoster being particularly common. Only three patients developed progressive multifocal leucoencephalopathy - a newly described disease ${ }^{2} 3$ which appears to be related to viral infection. ${ }^{4} 5$ The prevalence of cerebrovascular lesions was surprisingly low $(18 \%$ of all the neurological syndromes) though Currie and Henson acknowledge that this may be because they had no information on terminal vascular attacks at home.

The remaining neurological syndromes were a mixed group of metabolic disorders (such as uraemia, hepatic encephalopathy, and hypercalcaemia) and miscellaneous conditions such as entrapment neuropathies and amyloid neuropathy. Compression of the spinal cord and nerve roots was particularly common in myeloma, infection in Hodgkin's disease, and cerebral haemorrhage in acute leukaemia. Haemorrhage was generally associated with thrombocytopenia, while occlusive vascular disease was confined to polycythaemia vera. It is notable that intracranial metastatic deposits were very unusual in this series of patients. The low incidence of meningeal infiltration in acute leukaemia was especially surprising, and contrasts with that in other reports. $^{6}$

As treatment has been improving, neurological complications of haematological neoplasia are being encountered more frequently because of extended survival. ${ }^{7}$ Moreover, neurological symptoms may arise from lesions outside the nervous system. For example, deafness, tinnitus, or vertigo have been reported in 27 out of 100 consecutive patients with leukaemia, ${ }^{8}$ the cause being haemorrhage, lymphoid hyperplasia, or infection affecting the ear.

One aspect of this subject which is becoming increasingly important is the damage done to the nervous system by modern therapy. Vincristine neuropathy, radiation myelopathy, and cerebral haemorrhage due to thrombocytopenia induced by cytotoxic agents are all beginning to contribute appreciably to the neurological complications seen in these disorders. Similarly infection of the nervous system will probably increase as immunosuppressive drugs are employed in higher doses and more potent combinations. It has been suggested that intracranial lymphomas may themselves be produced by immunosuppressive therapy, for their prevalence is higher than expected in patients who have received transplants. ${ }^{9}$ Thus therapeutic advances against haematological neoplasia may enlarge rather than reduce the pattern of neurological complications.

1 Currie, S., and Henson, R. A., Brain, 1971, 94, 307.

2 Richardson, E. P., New England fournal of Medicine, 1961, 265, 815.

${ }^{3}$ Richardson, E. P., in Remote Effects of Cancer on the Nervous System, ed. W. R. Brain and F. H. Norris, p. 6. New York, Grune and Stratton, 1965.

4 Silverman, L., and Rubinstein, J. L., Acta Neuropathologica (Berlin), $1965,5,215$.

5 Woodhouse, M. A., et al., Brain, 1967, 90, 863.

' Pierce, M. I., in Pediatric Clinics of North America, 1962, 9, 425.

7 Evans, A. E., Gilbert, E. S., and Zandstra, R., Cancer, 1970, 26, 404

8 Shanbrom, E., and Finch, S. C., Yale fournal of Biology and Medicine,

1958, 31, 144.
Schneck, S. A., and Penn, I., Lancet, 1971, 1, 983.

\section{"Challenges for Change"}

There will be no overnight transformation of the National Health Service on 1 April 1974. Any improvement in the Service as a result of the forthcoming reorganization ${ }^{1-4}$ will take place gradually, and it could be five to ten years before the full effects of the reforms are felt. But is what the Government has proposed in its consultative documents enough? Judging from the essayists who have contributed to Challenges for Change 5 (see Supplement, 6 November, p. 27; 13 November, p. 31; and this week, p. 39) the answer is certainly not. In their introduction to the book Dr. John Revans and Mr. Gordon McLachlan put forward four proposals which specially merit the profession's attention: (1) "to develop a philosophy of health services where the rights, the duties and the expectations of every individual should be clearly set out without political or professional bombast;" (2) to define "a series of objectives for the N.H.S., including a theory on administration to attain them;" (3) the monitoring of the quality of health care; and (4) the development of a coherent manpower policy.

Overshadowing all these issues, however, is the question of finance. Earlier this year in a memorandum of evidence 6 to a parliamentary committee investigating health service expenditure the Department of Health lifted the curtain on how it produces the annual estimates for the health budget. To anyone with experience of the in-fighting for funds at all levels of the National Health Service the impression the memorandum gives of impreciseness in the estimating procedures will occasion no great surprise. Existing commitments, inflation, and pay increases seem largely to determine the annual budget. Events dictate policies, with an occasional shift of emphasis prompted by a public outcry about this or that health problem. The Department in explaining to the parliamentary committee the difficulties involved in forecasting its annual budget gives as the main reason "the existence of clinical freedom," claiming that this "substantially reduces the ability of the central authorities to determine objectives and priorities and to control individual facets of expenditure."

The quid pro quo for this clinical freedom for doctors is their collective duty to suggest improvements in health care, within the resources likely to be available in the next few years. In his essay Professor C. T. Dollery suggests how this might be done. He proposes an advisory service covering the whole N.H.S., comprising-initially - a health care committee and a health care research board. The board he sees as conducting comparative experiments in medical procedure, and the health care committee would assume responsibility for arranging medical audits, in the first instance on an experimental basis. Dr. D. H. Irvine in today's Supplement (p. 39) discusses the difficulties inherent in introducing checks into traditional areas of professional independence. Professor Dollery's proposals are controversial but they indicate one pathway to a coherent philosophy and clear objectives for the Health Service. While medical science has raced ahead with new discoveries leading to fresh and very often expensive treatments, the organization necessary for deciding which new treatment should be generally introduced and which used on an experimental basis, or even rejected, has fallen sadly behind.

In addition to this issue the essays range over many other topics such as consultant organization (with a special look at regional consultants), information systems, com- 